\title{
Development of an Efficient Agrobacterium Mediated Transformation Protocol for Sri Lankan Rice Variety - Bg 250
}

\author{
R.M.L.K. Ratnayake and G.H.C.M. Hettiarachchi ${ }^{1}$ \\ Department of Chemistry \\ Faculty of Science, University of Colombo \\ Sri Lanka
}

\begin{abstract}
Experiments were conducted to establish an efficient and simple protocol for regeneration and Agrobacterium mediated genetic transformation of an agronomically important indica rice variety Bg 250. Callus induction was achieved on modified $N_{6} B_{5}$ medium supplemented with 2,4 $-D(2.0 \mathrm{mg} / \mathrm{L}), B A P(1.0 \mathrm{mg} / \mathrm{L})$ and $N A A(1.0 \mathrm{mg} / \mathrm{L})$. The maximum callusing frequency of 90\% was observed after 21 days followed by 4 days of incubation on callus induction medium under dark. The highly prolific, nodular, compact yellowish large calli produced after 25 days were first checked for regeneration ability. Ninety five percent of regeneration frequency was observed with $N_{6} B_{5}$ medium supplemented with $3.0 \mathrm{mg} / L \mathrm{BAP}$ and $1.5 \mathrm{mg} / \mathrm{L} N A A$. Therefore, embryonic calli induced after 25 days were used for genetic transformation in subsequent experiments. Agrobacterium tumefaciens strain GV 3101 was transformed with pCAMBIA 1303 binary vector which contains hygromycin marker and GUS reporter gene. The transformed colonies were selected on $50 \mathrm{mg} / \mathrm{L}$ kanamycin and $25 \mathrm{mg} / \mathrm{L}$ rifampicin and confirmed by colony PCR. The PCR positive colonies were used to transform $B g 250$ rice calli. The maximum transformation efficiency of $20 \%$ was obtained using $500 \mathrm{mg} / \mathrm{L}$ cefotaxime as a bacteriostatic agent to inhibit growth of Agrobacterium. $100 \mu \mathrm{M}$ acetosyringone in co-cultivation medium and cocultivation for 3 days were the optimum conditions for maximum transformation. The expression of GUS gene revealed that the calli were successfully transformed.
\end{abstract}

Key words: Agrobacterium, Bg 250, Callus induction, Rice transformation.

\section{INTRODUCTION}

Rice is the most important crop in Sri Lanka occupying 34\% of the total cultivated area. There is an enormous need to improve the yield of local rice varieties in order to combat the food demands of increasing population. The most economical method of obtaining higher yield is increasing the productivity of local rice varieties rather than increasing the cultivated area. The improvement can possibly be achieved by genetic manipulation, which depends heavily on the use of in vitro techniques. Hence, the establishment of an effective in vitro plant regeneration system enables rapid production of fertile and genetically stable plants.

Plant tissue culture has become a useful tool to mass produce new transgenics. Callus induction is generally chosen for monocots such as rice. Khaleda and Al-Forkan (2006) reported that the mature seed scutellum is the best explant for callus induction and plant regeneration in rice. Identification and screening of useful cultivars for embryonic callus

${ }^{1}$ To whom correspondence should be addressed: chamanh@chem.cmb.ac.lk 
formation and subsequent in vitro plant regeneration are key steps in rice genetic improvement programs through application of biotechnology.

Although monocotyledonous plants were considered to be outside the Agrobacterium tumefacience host range (Raineri et al., 1990; Gould et al., 1991), successful transformation of rice by Agrobacterium was reported in the last decade. Chan et al., 1992 and 1993 showed regeneration of Agrobacterium-transformed calli from root explants and immature embryos those were the first reported transgenic rice plants obtained by inoculating immature embryos with Agrobacterium.

$\mathrm{Bg} 250$ is an improved Sri Lankan rice variety with high quality grains, resistance to leaf blast, bacterial leaf blight, thrips and brown plant-hopper. This is an ultra short duration variety that matures in about 80 days. $\mathrm{Bg} 250$ is suitable for drought and flood-prone areas. In the former, it can escape from drought, if planted early; in the latter, it can escape from flood if planted after the flood has receded, yielding well before the subsequent dry period. However, from all these characters it gives low yielding. The productivity of this variety can be increased by genetic manipulation. The main objective of this study was to develop an efficient Agrobacterium tumefaciens mediated transformation protocol for $\mathrm{Bg} 250$ Sri Lankan rice variety.

\section{MATERIALS AND METHODS}

\section{Plant material}

Seeds of $\mathrm{Bg} 250$ were obtained from Rice Research and Developmental Institute, Bathalagoda, Ibbagamuwa, Sri Lanka.

\section{Bacterial strain and plasmid}

Agrobacterium tumefaciens stain GV3101 was used for co-cultivation in the transformation protocol. Binary vector pCAMBIA1303 which is harbouring the $u$ diA gene encoding GUS ( $\beta$-glucuronidase) and the gene conferring hygromycin resistance was used for transformation.

\section{Callus induction}

The mature seeds of $\mathrm{Bg} 250$ were de-husked and surface sterilized by the protocol described by Rashid et al. (1996). The sterilized seeds were cultured on modified $\mathrm{N}_{6} \mathrm{~B}_{5}$ callus induction medium: $\mathrm{N}_{6}$ (Chu et al., 1975) macro- and micro-elements and $\mathrm{B}_{5}$ vitamins (Gamborg et al.,1968) ( $\mathrm{N}_{6} \mathrm{~B}_{5}$ medium), 2,4-D (2 mg/L), BAP (1 mg/L), NAA (1 mg/L), 3\% Sucrose and $0.8 \%$ agar at $\mathrm{pH}-5.8$. The cultured seeds were incubated for 14, 21 and 25 days in order to study the time required for maximum callusing.

\section{Transformation of Agrobacterium GV3101 and Colony PCR}

A super virulent Agrobacterium GV3101was transformed with pCAMBIA 1303 plant binary vector by freeze thaw method. Transformed colonies were confirmed by performing a colony PCR with 35S CaMV promoter specific primers. The colony PCR was carried out according to the protocol described by Hettiarachchi (2003). 


\section{Agrobacterium mediated callus transformation and regeneration}

Agrobacterium strain GV3101 carrying pCAMBIA1303 was grown to an optical density of $1.0\left(\right.$ O.D ${ }_{600 \mathrm{~mm}}=1.0$ ) in Luria Bertani (LB) medium containing $50 \mathrm{mg} / \mathrm{L}$ kanamycin and 25 $\mathrm{mg} / \mathrm{L}$ rifampicin. The culture was centrifuged at $3500 \mathrm{rpm}$ for $10 \mathrm{~min}$ and the pellet was resuspended in liquid $\mathrm{N}_{6} \mathrm{~B}_{5}$ medium, $2 \%$ sucrose, $1 \%$ glucose with different concentrations of Acetosyringone: $50,100,150 \mu \mathrm{M}(\mathrm{pH}-5.6)$. Twenty five day-old proliferated yellowish, nodular, compact embryogenic calli were used for transformation.

The calli were immersed in Agrobacterium cell suspension for 3, 5, 7 and $10 \mathrm{~min}$, and blotted on a sterile filter paper. The infected calli were transferred onto $\mathrm{N}_{6} \mathrm{~B}_{5}$ co-cultivation medium $\left(\mathrm{N}_{6} \mathrm{~B}_{5}\right.$ medium, 3\% Maltose, 1\% Glucose, 0.3\% Phytagel, 50, 100, $150 \mu \mathrm{M}$ Acetosyringone, $\mathrm{pH}-5.6)$ and incubated at $28^{\circ} \mathrm{C}$ for $1,2,3,4$ and 5 days in the dark in order to determine the best co-cultivation period. The co-cultivated calli were then washed 45 times with sterile distilled water and series of cefatoxime solutions with concentrations of $1 \mathrm{~g} / \mathrm{L}, 750 \mathrm{mg} / \mathrm{L}$ and $500 \mathrm{mg} / \mathrm{L}$. The washed calli were blotted on a sterile tissue paper and transferred to $\mathrm{N}_{6} \mathrm{~B}_{5}$ callus induction medium containing $0.3 \%$ Phytagel as the gelling agent and $250 \mathrm{mg} / \mathrm{L}, 500 \mathrm{mg} / \mathrm{L}, 750 \mathrm{mg} / \mathrm{L}$ cefotaxime. The calli were then transferred to $\mathrm{N}_{6} \mathrm{~B}_{5}$ selection medium: $\mathrm{N}_{6} \mathrm{~B}_{5}$ medium, 2,4-D $(2 \mathrm{mg} / \mathrm{L})$, BAP $(1 \mathrm{mg} / \mathrm{L})$, NAA $(1 \mathrm{mg} / \mathrm{L}), 3 \%$ Sucrose, $0.4 \%$ Phytagel, $50 \mathrm{mg} / \mathrm{L}$ Hygromycin, $500 \mathrm{mg} / \mathrm{L}$ Cefotaxime, $\mathrm{pH}-5.8$ (tested with 250, 500 and $700 \mathrm{mg} / \mathrm{L}$ Cefotaxime) and incubated for two weeks under dark in order to select transformed calli. After two weeks, green colour calli were transferred to fresh shoot regeneration medium; $\mathrm{N}_{6} \mathrm{~B}_{5}$ medium, BAP $(3.0 \mathrm{mg} / \mathrm{L}), \mathrm{NAA}(1.5 \mathrm{mg} / \mathrm{L}), 3 \%$ Maltose, Ascorbic acid $(0.2 \mathrm{~g} / \mathrm{L})$, Sorbitol $(0.1 \mathrm{~g} / \mathrm{L})$, Adenine sulphate $(0.1 \mathrm{~g} / \mathrm{L})$, Cysteine $(0.1 \mathrm{~g} / \mathrm{L})$, $0.4 \%$ phytagel , Hygromycin $(50 \mathrm{mg} / \mathrm{L})$, Cefotaxime $(500 \mathrm{mg} / \mathrm{L}), \mathrm{pH}-5.8$ (tested with 250 , 500 and $700 \mathrm{mg} / \mathrm{L}$ of Cefotaxime) and incubated under light. (Before regenerating the transformed calli, the regeneration frequency was checked). The well developed calli with shoot primordia were sub-cultured on $\mathrm{N}_{6} \mathrm{~B}_{5}$ shoot regeneration medium in jam jars and incubated at $28^{\circ} \mathrm{C}$ under continuous light.

Healthy shoots with defined stem were transferred to MS rooting medium: MS medium (Murashige and Skoog, 1962), 0.4\% phytagel, $50 \mathrm{mg} / \mathrm{L}$ Hygromycin, $500 \mathrm{mg} / \mathrm{L}$ Cefotaxime, pH-5.8 (tested with 250, 500 and $700 \mathrm{mg} / \mathrm{L}$ Cefotaxime) and incubated at $28^{\circ} \mathrm{C}$ under continuous light. The plantlets with well developed root system were planted in $250 \mathrm{~mL}$ plastic pots containing autoclaved mud that was collected from rice fields. The plantlets were established in such a way that the clump of plantlets originated from each callus was separated carefully and planted in several pots.

\section{Analysis of transformants}

The two week old transformed calli were screened histochemically for verification of the expression of uidA gene. The assay for GUS gene was carried out for selected calli. The calli were submerged in fixation buffer and vacuum infiltrated for 4-5 min on ice and kept at room temperature for $10 \mathrm{~min}$. The fixation buffer was removed and the material was washed twice with $50 \mathrm{mM}$ sodium phosphate buffer to remove fixative buffer. The tissue samples were stained with $1.5 \mathrm{mM}$ of X-gluc, $50 \mathrm{mM}$ sodium phosphate and $0.1 \%$ Triton $\mathrm{X}-100$ by vacuum infiltrating for $5-10 \mathrm{~min}$. and then kept at $37^{\circ} \mathrm{C}$ overnight in the dark. The calli which showed blue patches were recorded as positive transformants. 


\section{RESULTS AND DISCUSSION}

\section{Callus induction and regeneration}

Transformation of rice using Agrobacterium mediated methods and subsequent regeneration are dependent on several factors. Among them, the choice of explant, hormonal composition of the medium used and nutritional supplements highly affects the callusing and regeneration (Lin et al., 1995; Katiyar et al., 1999). Hiei et al. (1994) reported that scutellum derived callus was the most amenable explant for Agrobacterium mediated transformation. In the present study, mature rice seeds were used to obtain scutellum derived calli and the maximum callus induction frequency was obtained on modified $\mathrm{N}_{6} \mathrm{~B}_{5}$ medium containing 2 $2,4 \mathrm{D}(\mathrm{mg} / \mathrm{L})$, BAP $(1 \mathrm{mg} / \mathrm{L})$ and NAA $(1 \mathrm{mg} / \mathrm{L})$. Some reports recommended 2,4 D (6 $\mathrm{mg} / \mathrm{L}$ ) (Aldemita and Hodges, 1996; Lin and Jhang, 2005) however most reports recommended $2,4 \mathrm{D}(1.5-2.0 \mathrm{mg} / \mathrm{L})$ for callus induction which is confirmed by our results too. To study the time required for obtaining embryogenic calli, mature seeds were incubated on the callus induction medium for 14, 21 and 25 days and the calli obtained were then sub cultured on the same but fresh medium for 4 days. Twenty one days followed by four days were found to be the best time period for maximum callusing and callus induction frequency was $90 \%$. The resulting calli were yellowish, nodular, compact and highly prolific with $10.24 \mathrm{~mm}$ diameter (Fig. 1B).
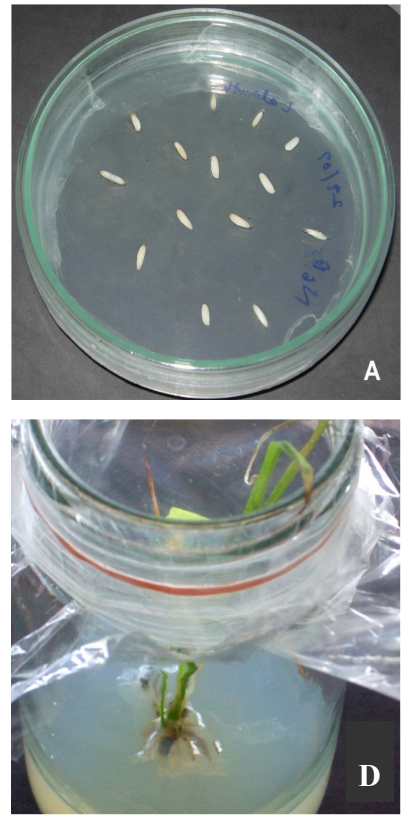
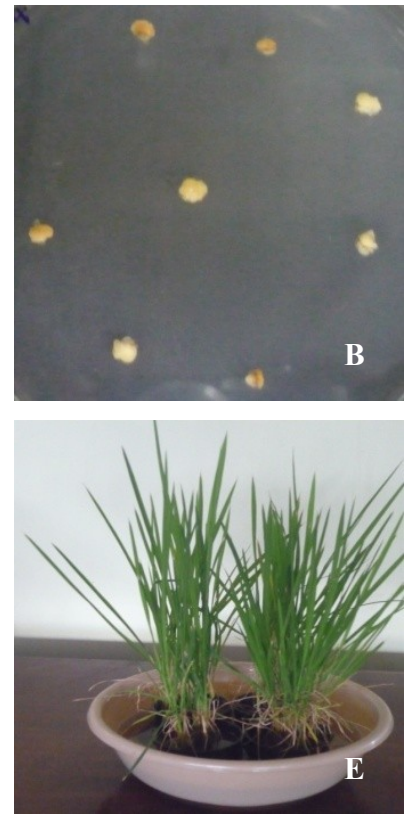
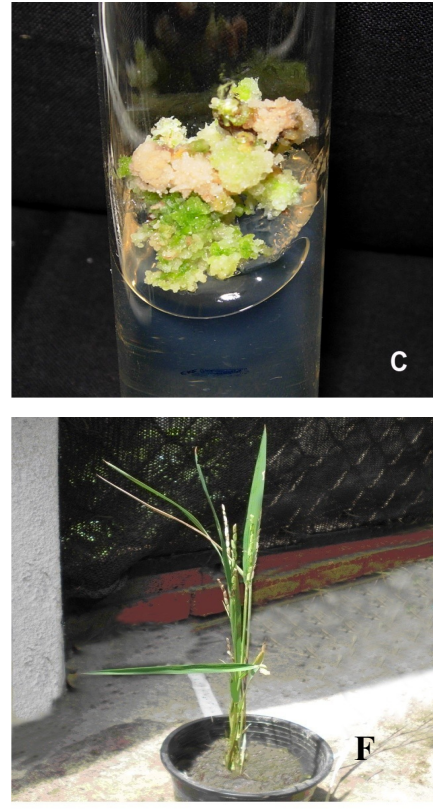

Fig. 1. Plant regeneration from scutellum derived callus in rice variety $\mathbf{B g} \mathbf{2 5 0}$

(A) De-husked, surface sterilized mature rice seeds on Callus Induction medium, (B) 21 days old scutellum derived calli on $\mathrm{N}_{6} \mathrm{~B}_{5}$ callus induction medium, (C) greenish, compact and well proliferated calli on shoot regeneration medium, (D) plantlets in rooting medium, (E) acclimatization under growth room conditions and (F) regenerated mature rice plant. 
The greatest difficulty one would encounter in rice tissue culture is the shoot regeneration or the organogenesis from the scutellum derived calli of rice seeds. Regeneration or organogenesis is highly dependent on its genotype. Therefore, before using the above calli in genetic transformation, it was necessary to confirm its regeneration ability. The best regeneration frequency of $95 \%$ was observed with $\mathrm{N}_{6} \mathrm{~B}_{5}$ medium supplemented with $3.0 \mathrm{mg} /$ $\mathrm{L}$ BAP and $1.5 \mathrm{mg} / \mathrm{L} \mathrm{NAA}$. In order to study the regeneration efficiency, 25 days old calli were treated under dark and light for two weeks. The calli incubated under light turned to green after 7 days but regeneration frequency was very poor compared to the dark treated ones. The dark incubated calli took two weeks to turn green. Green shoot buds with well developed leaf like structures were obtained after 7 to 10 days (Fig. 1C).

\section{Genetic transformation of rice callus}

Agrobacterium tumefaciens strain GV 3101 was transformed with pCAMBIA 1303 binary vector according to the protocol described by Holsters et al. (1978). Transformed colonies were selected on LB medium supplemented with $50 \mathrm{mg} / \mathrm{L}$ kanamycin and $25 \mathrm{mg} / \mathrm{L}$ rifampicin and then confirmed by colony PCR (Fig. 2). The transformed colonies resulting $123 \mathrm{bp}$ fragments from $35 \mathrm{~S}$ CaMV promoter specific primers were selected as positive colonies and they were used for transformation of rice calli.

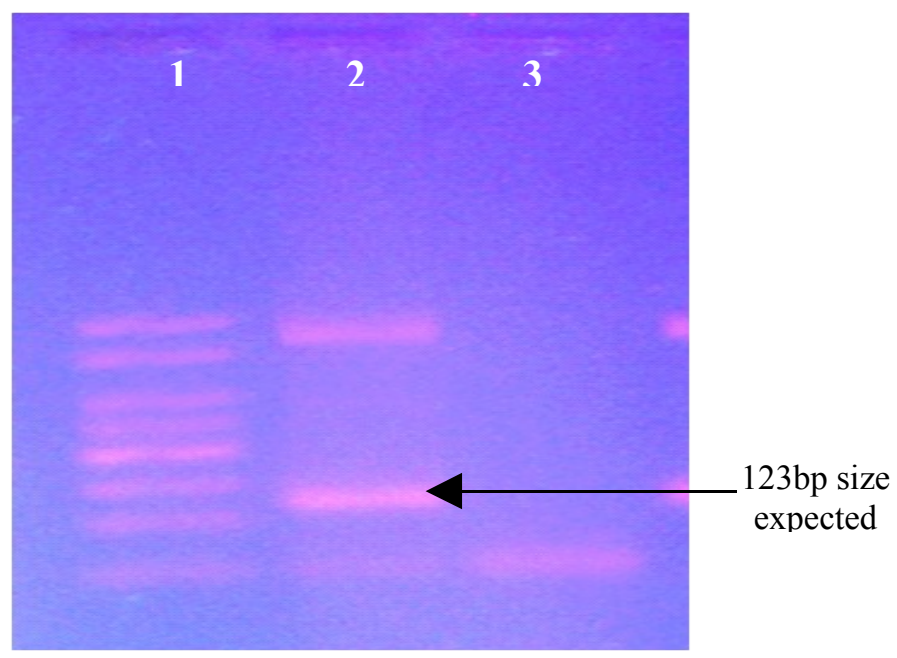

Fig. 2. Confirmation of the presence of CaMV $35 \mathrm{~S}$ promoter region in Agrobacterium tumefaciens strain GV3101 transformed with binary vector pCAMBIA1303.

Lane No 1: 50 bp ladder - Sizes ranging from 50, 100, 150, 200, 250, 300, 350, 400 bp , Lane No 2: Colony PCR product of Agrobacterium tumefaciens strain GV3101 transformed colony, and Lane No 3: Negative control

The temperature of incubation, duration of co-cultivation with Agrobacterium, concentration and the composition of bacteriostatic agent and duration of selection and concentration of antibiotic selection marker are the other factors reported which affect Agrobacterium mediated transformation of rice (Pollock et al., 1983; Dillen et al., 1997; Okkels and Pederson, 1998; Katiyar et al., 1999). To find the optimum conditions for co-cultivation, different concentration of acetosyringone and the duration of co-cultivation were tested. The 
frequency of hygromycine resistant calli obtained following each variation in co-cultivation conditions was taken as the transformation frequency. The presence of $100 \mu \mathrm{M}$ acetosyringine in co-cultivation medium and co cultivation for 3 days were found to be the most suitable for optimum transformation.

\section{Regeneration and analysis of transformants}

Compared to the non transformed calli regeneration frequency of 95\%, transformed calli showed very low regeneration frequency (30\%). Kumar et al. (2005) reported a transformation efficiency of $4.6 \%-5.5 \%$ and $6.4 \%-7.3 \%$ for two recalcitrant elite Indica rice cultivars, which were lower transformation frequencies than these results. Formations of embryogenic calli were enhanced with the use of high percentages of gelling agent (phytagel) and maltose as a carbon source (Kumar et al., 2005). The modified regeneration medium substituting agar with phytagel increased the regeneration frequency up to $73 \%$ and therefore all media used after transformation was substituted with phytagel. A bacteriostatic agent, cefotaxime was used to prevent Agrobacterium growth after co-cultivation. It has been reported that the use of high concentration of bacteriostatic agents may reduce the regenerability of the calli as they structurally resemble-auxins. Further, in combination with other callus inducing hormones such as 2,4 D may cause loss in regeneration potential (Lin et al., 1995; Okkels and Pederson, 1998). The green colour areas appeared on the middle of the calluses after 3 weeks (Fig. 3 B) and when transferred to regeneration medium later developed into tiny shoots (Fig. 3 C). In vitro regenerated shoots with defined stems were cultured on hormone free MS rooting medium for vigorous root development before transferring them into soil (Fig. 3D). After 6 days, a well developed root system was observed in the plantlets. The plantlets transferred to soil (Fig. 3 E) survived under the normal environmental conditions and grew to maturity. In order to confirm the presence of the transgene, few calli were subjected to histochemical staining. The CaMV 35S promoter used to drive the reporter gene (GUS) was found to be constitutively expressed in rice. Appearance of blue colour following overnight incubation at $37^{\circ} \mathrm{C}$ with GUS assay revealed the presence of the transgene and stable transgenic nature of the plants (Fig. 4). In this study stable genetic transformation by Agrobacterium mediated transformation protocol of $\mathrm{Bg} 250$ was demonstrated.

Therefore, this protocol can be modified in order to regenerate and recover transgenic rice plants of any rice variety. Modifications can be made at any stage i.e. before and after transformation with Agrobacterium (i.e pre-incubation treatment of calli, selection of transformed calli and shoot regeneration stages). Therefore the protocol used in the present study can be applied to rice callus induction and regeneration for breeding, transformation and other biotechnological applications. 

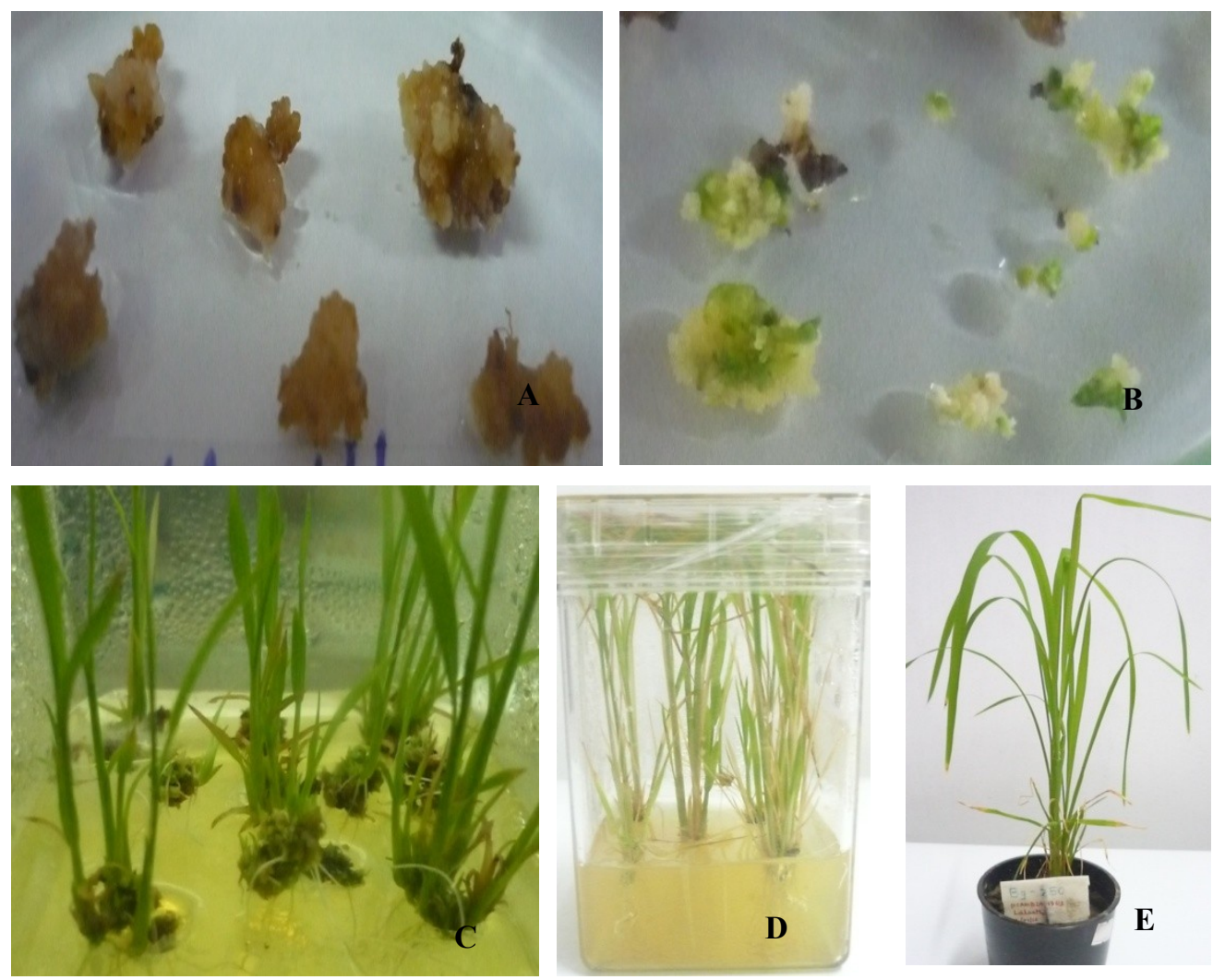

Fig. 3. Regeneration of transgenic Bg 250 from scutellum derived rice calli after Agrobacterium mediated transformation. (A) Scutellum derived calli on cocultivation medium (B) hygromicine resistant proliferating calli on shoot regeneration medium, $(C)$ regenerated shoots on shoot regeneration medium, (D) plantlets on rooting medium, and (E) acclimatization of Hygromicine resistant transformed $\mathrm{Bg} 250$ rice plantlet.
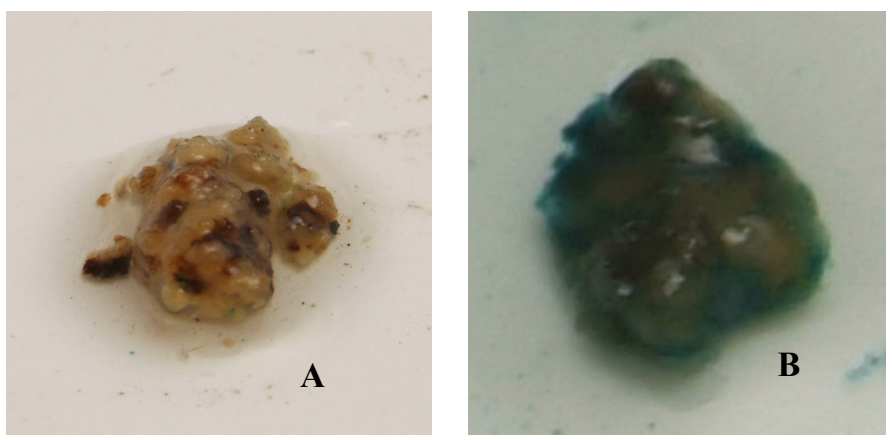

Fig. 4. Expression of GUS gene in two week old transformed rice calli when stained with X-gluc. (A) Untransformed callus and (B) transformed callus 
The calli obtained from mature rice embryos were be good explants for efficient in vitro plant regeneration. This study showed that, it is possible to obtain transgenic rice plants from scutellum derived calli of $\mathrm{Bg} 250$ variety under in vitro manipulation. The method described was simple, in expensive and does not require any advanced equipment.

\section{ACKNOWLEDGEMENTS}

The authors wish to acknowledge funding provided by the National Science Foundation (NSF) of Sri Lanka (Grant No: RG/2007/ BT /09), rice seeds provided by the Rice Research and Development Institute and laboratory (Department of Chemistry) and greenhouse assistance (Department of Plant Science) provided by the Faculty of Science, University of Colombo.

\section{REFERENCES}

Aldemita, R.R. and Hodges, T.K. (1996). Agrobacterium tumefaciens mediated transformation of japonica and indica rice varieties. Planta. 199,612-617.

Chan, M.T., Lee, T.M. and Chang, H.H. (1992). Transformation of indica rice (Oryza sativa L.) mediated by Agrobacterium tumefaciens. Plant Cell Physiol. 33, 577-583.

Chan, M.T., Chang, H.H., Ho, S.L., Tong, W.F. and Yu, S.M. (1993). Agrobacteriummediated production of transgenic rice plants expressing a chimeric $\alpha$-amylase promoter / Pglucuronidase gene. Plant Mol. Biol.22, 491-506.

Chu, C.C., Wang, C.C., Sun, C.S., Hsu, C., Yin, K.C., Chu, C.Y. and Bi, F.Y. (1975). Establishment of an efficient medium for anther culture of rice through comparative experiments on the nitrogen sources. Science Sinica.18, 659-668.

Dillen, W., Clercq, J.D., Kapila , J., Zambre, M.,Van Montagu, M. and Angenon, G. (1997). The effect of temperature on Agrobacterium tumefaciens gene transfer to plants. Plant J. 12, 1459-1463.

Gamborg, O., Miller, R. and Ojima, K. (1968). Nutrient requirement of suspension cultures of soybean root cells. Exp. Cell Res. 50, 151-158.

Gould, J.H., Devey, M., Hasegawa, O., Ulian, E.C., Peterson, G. and Smith, R.H. (1991). Transformation of Zea mays L., using Agrobacterium tumefaciens and the shoot apex. Plant Physiol. 95, 426-434.

Hettiarachchi, G.H.C.M. (2003) .Characterization of DNA Topoisomerase II promoter from Pisum sativum. Ph.D. Thesis, Jawaharlal Nehru University, India.

Hiei, Y., Shozo, O., Komari, T. and Kumashiro, T. (1994). Efficient transformation of rice (Oryza sativa L) mediated by Agrobacterium and sequential analysis of the boundaries of the T-DNA. Plant J. $6,271-282$. 
Holsters, M., Waele, D., Depicker, A., Messens, E., Van Montagu, M. and Schell, J. (1978). Transfection and transformation of A. tumefaciens. Mol. Gen. Genet. 168, 181-187.

Katiyar, S. K., Chandel, G., Singh, P. and Pratibha, R. (1999). Genetic variation and effect of 2,4-D in in vitro plant regeneration in indica rice cultivars. Oryza. 36, 254-256.

Khaleda, L. and Al-Forkan, M. (2006). Genotypic variability in callus induction and plant regeneration through somatic embryogenesis of five deepwater rice (Oryza sativa L.) cultivars of Bangladesh. AJB. 5, 1435-1440.

Kumar, K.K., Maruthasalam, S., Loganathan, M., Sudhakar, D. and Balasubramaniam, P. (2005). An improved Agrobacterium mediated transformation protocol for recalcitrant elite indica rice cultivars. Plant Mol. Bio. Rep. 23, 67 - 73.

Lin, J. J., Garcia, N.A. and Kuo, J. (1995). Plant hormone effect of antibiotics on the transformation efficiency of plant tissues by Agrobacterium tumefaciens cells. Plant Sci.109, 171-175.

Lin, Y. J. and Jhang, Q. (2005). Optimizing tissue culture conditions for high efficiency transformation of indica rice. Plant Cell Rep. 23, 540-547.

Murashinghe, T. and Skoog, F. (1962) A revised medium for rapid growth and bioassays with tobacco tissue cultures. Plant. Plysiol. 15 (3), 473-497.

Okkels, E.T. and Pederson, M.G. (1998). The toxicity of plant tissue and to Agrobacterium of some antibiotics. Acta Hortic. 225, 199-207.

Pollock, D., Barfield, K.G. and Shield, R. (1983). The toxicity of antibiotics to plant cell cultures. Plant Cell Rep. 2, 36-39.

Raineri, D.M., Bottino, P., Gordon, M.P. and Nester, E.W. (1990). Agrobacterium-mediated transformation of rice (Oryza sativa L.). Biotechnol. 8, 33-38.

Rashid, H., Yokoi, S., Toriyama, K. and Hinata, K. (1996). Transgenic plant production mediated by Agrobacterium in Indica rice. Plant Cell Rep. 15, 727-730. 